\title{
Malaria and intestinal parasitosis among children presenting to the Paediatric Centre in Sana'a, Yemen
}

A.A. Azazy ${ }^{1}$ and Y.A. Raja'a ${ }^{2}$

$$
\begin{aligned}
& \text { الملاريا والطفيليات المعوية في الأطفال الذين يراجعون مستشفى الأطفال المركزي في حنعاء، اليمن }
\end{aligned}
$$

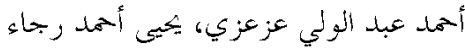

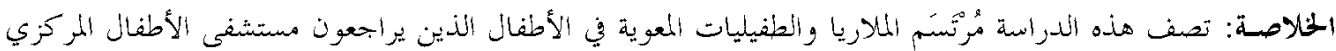

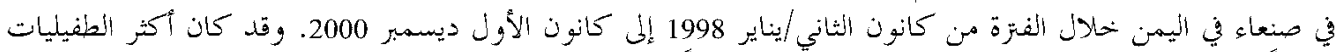

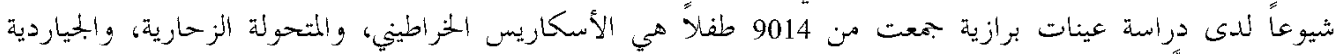

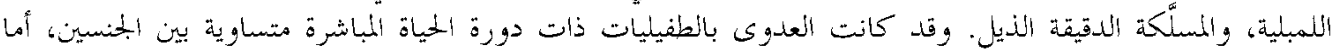

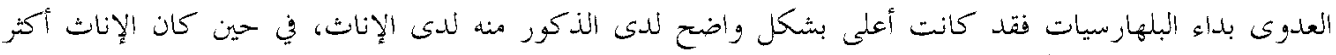

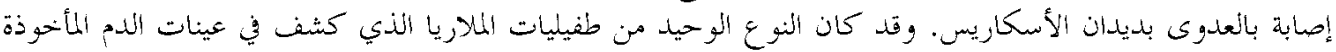

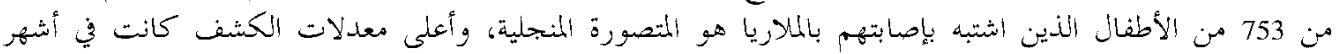

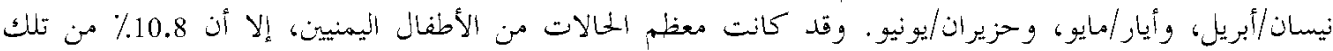

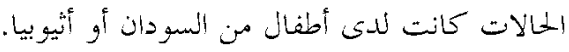

ABSTRACT We studied the profile of malaria and intestinal parasitosis among children presenting to the Paediatric Health Centre in Sana'a from January 1998 to December 2000. In stool samples from 9014 children, Ascaris lumbricoides, Entamoeba histolytica, Giardia lamblia and Trichuris trichiura were the most common. Infection with parasites of direct life-cycle were similar in boys and girls. Schistosome infection was significantly higher in boys than girls, but girls were more infected with ascariasis. The only species of malaria parasite found in blood samples from 753 children with suspected malaria was Plasmodium falciparum, with the highest rates in April-June. The majority of positive cases were Yemeni children, but $10.8 \%$ were Sudanese or Ethiopian.

Le paludisme et la parasitose intestinale chez les enfants consultant au centre pédiatrique de Sanaa (République du Yémen)

RESUME Nous avons étudié le profil du paludisme et de la parasitose intestinale chez des enfants amenés en consultation au centre pédiatrique de Sanaa de janvier 1998 à décembre 2000. Ascaris lumbricoides, Entamoeba histolytica, Giardia lamblia et Trichuris trichiura étaient les parasites les plus courants. L'infestation par des parasites qui ont un cycle de vie direct était similaire chez les garçons et les filles. L'infestation par des schistosomes était significativement plus élevée chez les garçons que chez les filles, tandis que les filles étaient davantage touchées par l'ascaridiase. Plasmodium falciparum était la seule espèce de parasite du paludisme trouvée dans les échantillons sanguins de 753 enfants suspects de paludisme, les taux les plus élevés entre avril et juin. La majorité des cas positifs étaient des enfants yéménites, mais 10,8\% étaient des Soudanais ou des Ethiopiens.

${ }^{1}$ Department of Parasitology; ${ }^{2}$ Department of Community Medicine, Faculty of Medicine and Health Sciences, Sana'a, Yemen.

Received: 14/08/02; accepted: 16/03/03 


\section{Introduction}

The highest rates of protozoa and helminth infections worldwide occur in the tropics. The distribution of these infections depends on conditions such as a suitable climate and human activities such as population movements and poor sanitation.

Malaria is the major public health problem in Yemen [1], and has the typical afrotropical pattern in which the predominant species is Plasmodium falciparum [2,3]. A previous study found that the incidence of $P$. falciparum infection among Yemeni returnees in Al-Hodeidah governorate was $13.9 \%$, with some seasonal variations [3].

Transmission of ascariasis and trichuriasis takes place throughout the year in regions with a temperate climate. The soil-transmitted parasites, mainly Ascaris lumbricoides and Trichuris trichiura, are usually more prevalent where there is favourable soil, warmth and moisture together with poor sanitation. Studies in different parts of Yemen have reported prevalence rates of ascariasis ranging from 16\%-68\% [4-6]. Meanwhile, trichuriasis was reported, mostly from the same areas, in $1 \%-21 \%$ of the population [6,7].

Parasites with a direct life-cycle spread more easily among children and within the household. Various studies in Yemen have been conducted on the different parasites with a direct life-cycle. For example, the prevalence of Entamoeba histolytica has been reported to range from $1.7 \%-36 \%$ [4,7], while for Giardia lamblia it was 9.0\%-20.5\% and for Hymenolepis nana $2 \%-8.3 \%[6,8]$. The lowest prevalence was $0 \%-2 \%$ for Enterobius vermicularis $[4,6]$.

The most prevalent water-borne parasite in Yemen is the schistosome. Schistosomiasis is second to malaria in the list of major public health problems in the country
[1] and intestinal schistosomiasis has been reported in a number of different surveys [6-12]. Very low rates of infection have been reported for Fasciola hepatica, from $0.5 \%-2.0 \%[4,7]$. Low prevalence rates of $0.1 \%-0.3 \%$ were reported for Taenia spp. [4,7].

With the exception of Farag's study in 1985 [4], all other published works from Yemen have focused on schoolchildren and children in the community. None of the studies focused on children at the hospital level and none has investigated malaria transmission in Sana'a, the city capital of the country. The current study therefore aimed to determine the profile of malaria and intestinal parasitic infections among children attending the Paediatric Health Centre in Sana’a.

\section{Methods}

The Paediatric Health Centre in Sana'a provides services to the community through outpatient clinics and admissions. The centre receives patients from Sana'a city, surrounding areas and sometimes from other governorates, as well as referred cases from private clinics. Children with suspected infections are referred to the laboratory unit for investigation. In a record-based descriptive study, we reviewed the results of 9014 stool samples from Yemeni children and 753 blood samples from Yemeni and other nationality children who had been referred to the laboratory unit during the period January 1998 to December 2000. For malaria, additional questions about residence, nationality and travel history to known endemic areas were investigated and recorded in the laboratory notes. All stool and blood samples were examined in the centre's laboratory.

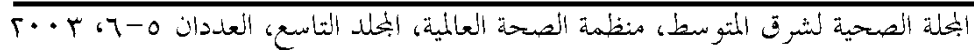


Children being investigated for intestinal protozoa or helminth infections provided a stool sample. A normal saline sedimentation technique was adopted for stool examination. Formal ethyl acetate sedimentation or direct smear methods were also used when necessary. For children who complained of pruritis ani or nocturnal enuresis, transparent adhesive tape was used to take anal swabs.

Children suffering febrile illnesses and suspected of having malaria were asked to give a blood sample. Thick and a thin blood films were prepared for each case. Thin films were fixed with absolute methanol and stained with $3 \%$ Giemsa diluted in $\mathrm{pH}$ 7.2 buffered water for 30 minutes. Thick films were stained unfixed.

The data were analysed using Epi-Info, version 6 .

\section{Results}

The age of the children ranged from 2 months to 14 years.

\section{Malaria}

Of 753 children examined for suspected malaria (484 boys and 269 girls), 130 (17.3\%) were positive for malaria. The only species of malaria parasite identified was $P$. falciparum. The distribution of infection among the cases by age group, sex and nationality is shown in Table 1 . Twice as many boys $(66.9 \%)$ as girls $(33.1 \%)$ were infected. The highest rate of infection was in the age group 6-10 years. The majority of children testing positive (89.2\%) were Yemeni, but $8.5 \%$ were Sudanese and $2.3 \%$ were Ethiopian. Most of the positive cases lived in Hezyaz, $25 \mathrm{~km}$ south of Sana'a, but some came from Arrowdhah on the opposite side of the city; some positive cases had never been out of the Sana'a area.

\begin{tabular}{|c|c|c|}
\hline \multicolumn{3}{|c|}{$\begin{array}{l}\text { Table1 Sex, age and nationality distribution } \\
\text { of } 130 \text { children with a diagnosis of } \\
\text { Plasmodium falciparum infection }\end{array}$} \\
\hline \multirow[t]{2}{*}{ Variable } & \multicolumn{2}{|c|}{ Children infected $(n=130)$} \\
\hline & No. & $\%$ \\
\hline \multicolumn{3}{|l|}{ Sex } \\
\hline Male & 87 & 66.9 \\
\hline Female & 43 & 33.1 \\
\hline \multicolumn{3}{|l|}{ Age (years) } \\
\hline $0-5$ & 15 & 11.5 \\
\hline $6-10$ & 89 & 68.5 \\
\hline $11-14$ & 26 & 20.0 \\
\hline \multicolumn{3}{|l|}{ Nationality } \\
\hline Yemeni & 116 & 89.2 \\
\hline Sudanese & 11 & 8.5 \\
\hline Ethiopian & 3 & 2.3 \\
\hline
\end{tabular}

$\mathrm{n}=$ total number of infected children.

The highest seasonal rates of infection were recorded in the months June, May and April respectively (Figure 1).

\section{Intestinal parasites}

Of 9014 children examined, 2477 (27.5\%) positive tests for intestinal parasites were found. The intestinal parasites detected among infected children are shown in Table 2. With the exception of Schistosoma mansoni and Taenia saginata, most of the intestinal parasites were those with a feco-oral route of transmission. Four different parasites, A. lumbricoides, E. histolytica, G. lamblia and T. trichiura, had the highest rates.

Overall, the infection rate was significantly higher among girls (1192, 31.5\%) than boys (1285, 24.6\%) $(P<0.001)$. Parasites with a direct life-cycle showed a similar sex distribution. However, the rate of A. lumbricoides infection among girls was significantly higher than that among boys. In contrast, the infection rate with $E$. histolytica was significantly higher among boys than that among girls $(P<0.001)$. 


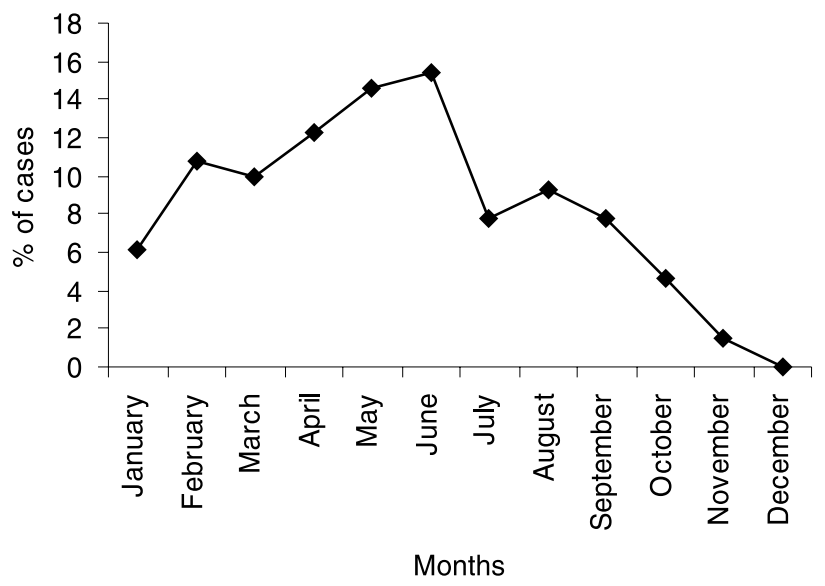

Figure 1 Monthly distribution of cases among 130 children diagnosed with Plasmodium falciparum infection

\section{Discussion}

Our study revealed a parasite infection rate of $17.3 \%$ among children tested for malaria. The species of malaria found was exclusively $P$. falciparum. This is consistent with the documented pattern of malaria in Yemen, which is classified as afro-tropical with $P$. falciparum as the predominant species. Previous studies in Yemen have found that $P$. falciparum constitutes $90 \%-95 \%$ of all diagnosed malaria cases [2,3]. The infection rates were highest in June, May and April respectively. This finding indicates that malaria in Sana'a city may have its own pattern of seasonality that is different from Al-Hodiedah governorate.

The present study revealed that $10.8 \%$ of the malaria cases were children from Sudan and Ethiopia who may be either immigrants or indiginous. Interestingly, some positive cases in our study had never been out of the Sana'a area, which is supposed to be a non-malarial area due to its high altitude (2400 m above sea level). Most of the positive cases were children living in an area called Hezyaz, about $25 \mathrm{~km}$ to the south of Sana'a, which lies on the road that connects the capital with two endemic areas, Taiz and Hodeidah cities. The main activity of the population in Hezyaz, beside agriculture, is serving food for travellers. Therefore, it can be hypothesized that infected mosquitoes hidden in vehicles are responsible for transmission of the disease. Another possibility is that transmission of malaria is taking place in Sana'a city itself. This is backed up by the fact that some cases also came from another area on the opposite side of the city called Arrowdhah.

With the exception of $S$. mansoni and Taenia saginata, the intestinal parasites diagnosed in the current study are those with a feco-oral route of transmission. It was expected that the infection rate with intestinal parasites would be similar among boys and girls. Surprisingly, however, the infection rate among girls was greater than that among boys. Parasites with a direct lifecycle were found to have a similar sex distribution. This was not the case with $S$. mansoni, where the rate among boys was higher than that among girls. This can be

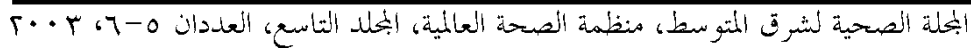


Table 2 Pattern of intestinal parasites detected in 9014 tests for parasitic infections among children

\begin{tabular}{|c|c|c|c|c|c|c|c|c|}
\hline \multirow[t]{3}{*}{ Parasite } & \multicolumn{7}{|c|}{ Positive test } & \multirow{3}{*}{$P$-value } \\
\hline & \multicolumn{2}{|c|}{ Boys $(n=1285)$} & \multicolumn{2}{|c|}{ Girls ( $n=1192)$} & \multicolumn{2}{|c|}{ Total $(n=2477)$} & \multirow[t]{2}{*}{$\chi^{2}$} & \\
\hline & No. & $\%$ & No. & $\%$ & No. & $\%$ & & \\
\hline Ascaris lumbricoides & 235 & 18.3 & 286 & 23.9 & 521 & 21.0 & 42.0 & $<0.001$ \\
\hline Entamoeba coli & 258 & 20.0 & 248 & 20.8 & 506 & 20.4 & 0.83 & 0.36 \\
\hline Giardia lamblia & 226 & 17.6 & 188 & 15.8 & 414 & 16.7 & 5.14 & 0.023 \\
\hline Trichuris trichiura & 201 & 15.6 & 180 & 15.0 & 381 & 15.4 & 0.68 & 0.44 \\
\hline Entamoeba histolytica & 160 & 12.5 & 129 & 10.8 & 289 & 11.7 & 6.15 & 0.013 \\
\hline Hymenolepis nana & 149 & 11.6 & 123 & 10.3 & 272 & 11.0 & 3.84 & 0.05 \\
\hline Schistosoma mansoni & 37 & 2.9 & 16 & 1.3 & 53 & 2.1 & 26.1 & $<0.001$ \\
\hline Enterobius vermicularis & 13 & 1.2 & 20 & 1.7 & 33 & 1.3 & 3.78 & 0.052 \\
\hline Fasciola hepatica & 4 & 0.3 & 2 & 0.2 & 6 & 0.2 & 1.95 & 0.16 \\
\hline Taenia saginata & 2 & 0.2 & 0 & 0 & 2 & 0.1 & NA & NA \\
\hline Total & 1285 & 24.6 & 1192 & 31.5 & 2477 & 27.5 & 52.5 & $<0.001$ \\
\hline
\end{tabular}

$\mathrm{n}=$ total number of tests.

NA = not applicable.

attributed to boys having more activities involving contact with water than girls through swimming and ablutions. As for ascariasis, the rate of infection was higher among girls than that among boys. This can be explained by girls being involved more with food preparation than boys, exposing them to raw foods contaminated with larvated eggs.

\section{Conclusions}

High rates of infection with protozoa and helminth parasites denote high levels of pol- lution in the environment of the study area. More efforts are needed to improve environmental sanitation in Sana'a in order to reduce the rate of infection with intestinal parasites. To our knowledge, this is the first report that shows some evidence that malaria is being transmitted in Sana'a city. A special study to confirm or refute the suggestion that the vector for malaria is breeding in Sana'a is urgently needed.

\section{References}

1. Year plan of health development 19962000. Sana'a, Yemen Ministry of Public Health, 1995:29.

2. Azazy AA, Al-Dulaimi SS, Basil FA. Prevalence of malaria among patients seen at the Public Health Laboratory in 1994 to 1995 in Sana'a. Yemen medical journal, 1998, 2:59-63.

3. Assabri AM et al. Chloroquine-resistant malaria in Yemeni returnees in 
Hodiedah, Republic of Yemen. Journal of the Arab Board of Medical Specializations, 2001, 3:88-93.

4. Farag HF. Intestinal parasitosis in the population of the Yemen Arab Republic. Tropical and geographical medicine, 1985, 37:29-31.

5. Raja'a YA et al. Schistosomes infection rate in relation to environmental factors in schoolchildren. Saudi medical journal, 2000, 21(7):635-8.

6. Azazy AA, Al-Taiar AS. A study survey on intestinal and blood parasites among schoolchildren in Sana'a province, Yemen. Saudi medical journal, 1999, 20(6):422-4.

7. Raja'a YA et al. Some aspects in the control of schistosomosis and soil-transmitted helminthosis in Yemeni children. Saudi medical journal, 2001, 22(5):42832.

8. Azazy AA, Al-Dullaimi SS. Prevalence of intestinal parasites of pupils of an elementary school in Haja town, Yemen. Yemen medical journal, 1999, 3:66-8.
9. Hazza YA, Arfa'a F, Haggar M. Studies in Schistosomiasis in Taiz province, Yemen Arab Republic. American journal of tropical medicine and hygiene, 1983, 32: 1023-8.

10. Nagi MA, Molan AL. Schistosomiasis among schoolchildren in Marib province of Republic of Yemen. International medical journal, 1992:3212.

11. Al-Haddad AM, Assabri AM. Health impact of uncompleted sewerage project in Maitam valley, Ibb town, Republic of Yemen. Yemen medical journal, 1998, 2:68-76.

12. Schaap HB, Den Dulk MO, Polderman AM. Schistosomiasis in the Yemen Arab Republic. Prevalence of Schistosoma mansoni and S. haematobium infection among school children in the central highlands and their relation to altitude. Tropical and geographical medicine, 1992, 44:19-22.

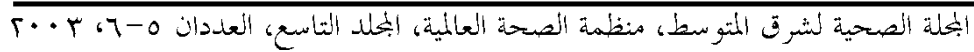

